\section{Tests of frustration theory extended to the generalized PRE}

\author{
WILLIAM WATERS and PAUL D. KNOTT \\ University of Denver, Denver, Colo. 80210
}

Within the context of frustration theory, Amsel and his associates $(1966,1968)$ offer two explanations for the finding that PRE-like extinction is obtained with both CRF and PRF conditions in a within-S design. Both hypotheses were put to partial tests in the present study and support was found for the "stimulus generalization" notion but not for the "generalization of persistence effect" notion.

Amsel, Rashotte, \& MacKinnon (1966) offer two explanations for the finding that the PRE normally obtained in between-S designs occurs with both CRF and PRF conditions in within-S designs. One explanation is that the within-S design permits stimulus generalization from one alley to the other during acquisition, even though a distinctive discriminandum is furnished. That is, it is supposed that the black alley (100\% reinforcement) and the white alley $(50 \%)$ are similar enough that some conditioned fractional anticipatory frustration ( $\mathrm{r}_{\mathrm{F}}-\mathrm{sF}$ ) generalizes from the white to the black alley during acquisition. Some support for this explanation can be found in the acquisition data of within-S designs, where the separation of the PRF and CRF curves at asymptote is less than the separation of those curves in a between-S design (Amsel et al, 1966). Rashotte \& Amsel (1968) attempted to inhibit this generalization by furnishing more than the usual single discriminandum (color), but they failed to obtain a significant difference between the CRF and PRF conditions in extinction.

The second explanation involves the generalization of $\mathrm{r}_{\mathrm{F}}-\mathrm{SF}_{\mathrm{F}}$ from the PRF alley to the CRF alley in extinction. While $\mathrm{r}_{\mathrm{F}}-\mathrm{SF}$ is developed only in PRF Ss in a between-S design, it is present, in the same $S$, under both conditions in a within $S$ design. Thus, as soon as either stimulus elicits $\mathrm{rF}_{\mathrm{F}}$ in extinction, the $s_{F}$ stimulus cues are elicited, regardless of whether the external stimuli have been associated with CRF or PRF in acquisition. Even though, therefore, certain stimuli have been associated with CRF in acquisition, the extinction data under CRF conditions should approximate extinction under PRF stimulus conditions; i.e., extinction data in both PRF and CRF alleys should display the typical PRF persistence effect, which is the usual finding with within-S designs. Some partial support for this latter hypothesis has been provided by Amsel et al (1966), who point out that these two hypotheses are not necessarily mutually exclusive but may complement each other.
The purpose of the present study is to examine further the above two hypotheses offered by Amsel et al (1966). One way to test the stimulus generalization hypothesis is to create a variety of differences between the PRF and CRF conditions. In order, therefore, to minimize the generalization from $S_{1} \pm$ to $S_{2} \ddagger$ and thus "prevent" the PRE from developing within the CRF condition in a within- $S$ design, the alleys $S_{1}$ and $S_{2}$ in this study differed in height, width, color, and texture of walls and floor. In addition, several variables similar to those employed by Rashotte \& Amsel (1968) were also manipulated: time of day for running CRF and PRF conditions, background noise, and gloves. vs bare hands. Between-S control groups were also run in these $S_{1}$ and $S_{2}$ alleys.

The second explanation presents a major problem for testing: when extinction trials begin, the absence of reward in and of itself is responsible for the generalization process; therefore, the inhibition of this generalization process is made difficult if not impossible by the very nature of the extinction process that is being examined. It may be possible, however, to enhance this generalization. Wagner (1963) has demonstrated that it is possible to condition the $\mathrm{rF}_{\mathrm{F}} \mathrm{SF}$ mechanism to neutral stimuli. By employing his technique (presenting a neutral CS on nonreward trials in PRF training and in extinction in both alleys), it should be possible to strengthen the generalization of the "persistence effect" from the PRF to the CRF alley, thereby demonstrating that this mechanism is involved in the within-S phenomenon under study.

\section{SUBJECTS}

The Ss were 40 experimentally' naive Long-Evans Agouti male hooded rats that were 90 days old at the beginning of the experiment.

\section{APPARATUS}

The apparatus consisted of two runways, $R 1$ and $R 2$, each 36 in. in length, each of which could be aligned with a common startbox (SB). The SB was $12 \times 3 \times 4$ in. high; its floor was made of $1 / 2$-in. hardware cloth, and its top of clear Plexiglas was hinged for easy access. The runways were made of an alley section (A1 or A2) and a goalbox section (GB1 or GB2). The latencies in the alley sections were measured by a Hunter clock counter that was controlled by two photoelectric cells, $P 1$ and P2, which were located 1 in. from the SB door and 1 in. from the GB door, respectively.

R1 and R2, according to experimental plan, were as different as was practicable in all aspects except length. A1 and GB1 (comprising R1) were $3 \frac{3}{4}$ in. high $\times 3$ in. wide. The walls were of $1 / 2$-in. half-rounds. The floor was of $1 / 2$-in. hardware cloth. The top was made of clear $1 / 4-i n$. Plexiglas, hinged to one side of the alley. The other runway, R2 (A2 and GB2), was $2 \frac{3 / 4}{4}$ in. high $X 4$ in. wide; the walls were of $1 / 2$-in. plywood covered with flat black Formica, smooth in texture; the floor was solid and covered with black Formica. The top was $1 / 4$-in. Plexiglas hinged to one side.

The two nunways were alike in having gray guillotine doors between SB and the alleys and between the alleys and the goalboxes, to prevent retracing. Also, each GB was fitted with a $1 \frac{1}{2}-$ in. speaker mounted on the end, for providing the $10,000-\mathrm{Hz}$ tone to act in combination with a $1 \frac{1}{2}-W$ light bulb mounted on the underside of the hinged top as the CS. The light and tone were operated by a series switching arrangement consisting of a toggle switch and a photoelectric cell (P2), set up so that the CS was automatically operated by $\mathrm{P} 2$ for the appropriate group on nonreward trials.

The background noise discriminandum consisted of tape-recorded music played at a constant volume for one condition and a "no sound" (tape recorder turned off) alternate condition.

\section{PROCEDURE}

One week before the beginning of running, all Ss were placed on a 12-h food-deprivation schedule. During this period, each $S$ received $5 \mathrm{~g}$ of Purina Lab Chow twice a day in his home cage with ad lib water and was handled for $2 \mathrm{~min}$ daily.

The $40 \mathrm{Ss}$ were randomly assigned to groups of 10 and subgroups of 5 . The subgrouping was for counterbalancing purposes, i.e., half of each experimental group was run on a $\mathbf{R}_{1} \pm, \mathbf{R}_{2} \pm$ paradigm and the other half on a $R_{2} \pm, R_{1} \pm$ paradigm. Each paradigm included an assigned condition of either barehanded or gloved E, noise or no noise, and a.m. or p.m. running time. Morning trials were run between 8 a.m. and 11 a.m., evening trials between 8 p.m. and 11 p.m. The food reward consisted of five $.045 \mathrm{-g}$ Noyes pellets. All Ss were confined to the goalbox 


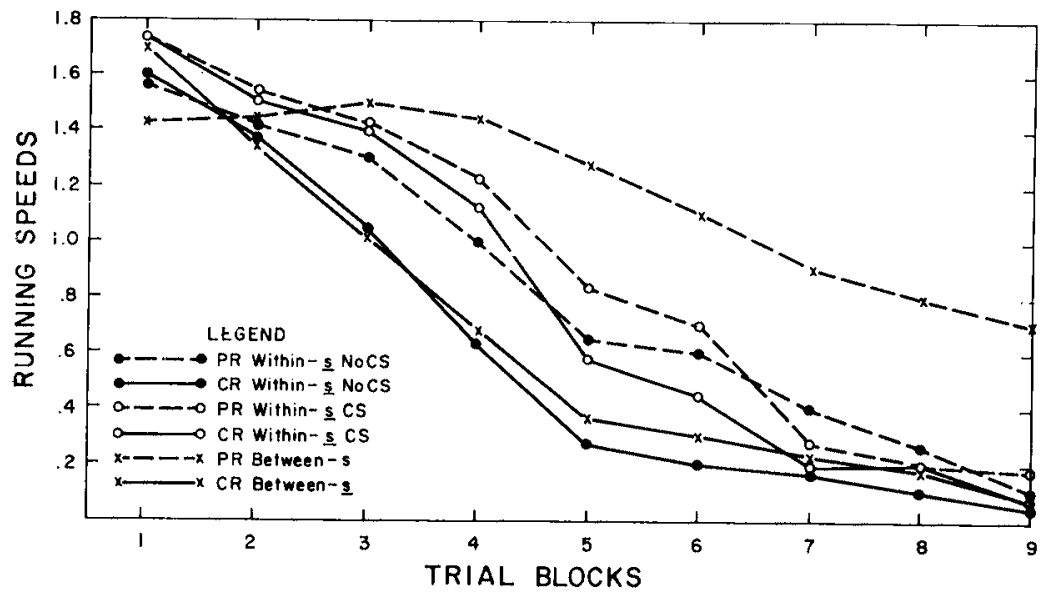

approximately $30 \mathrm{sec}$ on all trials. The intertrial interval was a minimum of $15 \mathrm{sec}$.

The experiment involved a total of 208 acquisition trials for the within-S groups ( 1 and 2) and 104 acquisition trials for the between-S groups (3 and 4 ). Each $S$ in Groups 1 and 2 was run 104 trials to the CRF stimulus condition and 104 trials to the PRF stimulus condition, while the Ss in Groups 3 and 4 were run 104 trials under the PRF or the CRF condition. The pattern of reward and nonreward trials under PRF conditions was the same as that used by Wagner (1963) and the same for both groups. The Ss in Groups 1 and 2 were run four trials per day under each condition (PRF and CRF); Group 3 was run four trials per day on PRF and Group 4 was run four trials per day on CRF. There were 72 extinction trials for Groups 1 and 2 and 36 extinction trials for Groups 3 and 4. The CS (light and tone) was presented to Group 2 on each nonreward trial in both acquisition and extinction.

\section{RESULTS AND DISCUSSION}

The latency data were transformed to running speeds by calculating the
Fig. 1. Mean running speeds over blocks of four extinction trials for all groups.

the typical significant main effect of PRF vs $\mathrm{CRF}(\mathrm{F}=13.04, \mathrm{df}=1 / 18, \mathrm{p}<.01)$ and a significant interaction between trial blocks and reinforcement $(F=13.393$, $\mathrm{df}=8 / 144, \mathrm{p}<.01)$. These effects should be sufficient to dimonstrate that the apparatus and procedure, in and of itself, produced no effects that would be inconsistent with previous findings.

The results of this study thus lend support to the Amsel et al (1966) hypothesis that stimulus generalization from one alley to the other is responsible for the increased resistance to extinction found under CRF conditions in a within-S design. When the similarity between the alleys was reduced, thereby facilitating the discrimination between the CRF and PRF conditions, the resistance to extinction under the CRF condition was decreased. No evidence, however, was found to support the "persistence effect" hypothesis. Given the difficulty in testing this latter hypothesis (i.e., the difficulty in clearly refuting it) and the lack of clear supporting data, it would seem desirable to clarify the hypothesis so that further testing could occur. A clearer case for or against the stimulus generalization hypothesis could be made if the present study were replicated with the addition of a control group in which Ss were run on a single black-white discriminandum.

\section{REFERENCES}

AMSEL, A., RASHOTTE, M., \& MacKINNON, J. Partial reinforcement effects within subjects and between subjects. Psychological Monographs, 1966, 20(Whole No. 628).

RASHOTTE, M., \& AMSEL, A. Generalized PRE: Within-S PRF and CRF training in different runways at different times of day with different experimenters. Psychonomic Science, 1968, 11, 315-316.

WAGNER, A. Conditioned frustration as a learned drive. Journal of Experimental Psychology, 1963, 64, 142-148. 